DOI: 10.12731/2658-6649-2020-12-1-64-70

УДК 504.062

\title{
ОЦЕНКА ЗАГРЯЗНЕНИЯ ХЛОРИД-ИОНАМИ МАЛЫХ РЕК НИЖНЕВАРТОВСКОГО РАЙОНА
}

\author{
Алагулов Д.А., Иванова А.В.
}

Важное значение в оценке экологической ситуащии в Ханть-Мансийском автономном округе представляют конщентрации химических веществ в поверхностных водах и донных отложениях, которые характеризуют техногенные потоки загрязняющих веществ в районах нефтепромыслов. Хлоридное загрязнение малых рек приводит к их накоплению в донных отложениях. Высокие концентрации хлорид-ионов в поверхностных водах и донных отложениях негативно воздействуют на речную экосистему.

Ключевые слова: реки; поверхностные воды; донные отложения; хлориды; загрязнение.

\section{ASSESSMENT OF CHLORIDE ION POLLUTION OF SMALL RIVERS IN THE NIZHNEVARTOVSK REGION}

\author{
Alagulov D.A., Ivanova A.V.
}

The importance in assessing the environmental situation in the Khanty-Mansi Autonomous Okrug is represented by the concentration of chemicals in surface waters and bottom sediments, which characterize the technogenic flows of pollutants in the areas of oil fields. Chloride pollution of small rivers leads to their accumulation in bottom sediments. High concentrations of chloride ions in surface waters and bottom sediments adversely affect the river ecosystem.

Keywords: rivers; surface waters; bottom sediments; chlorides; pollution.

\section{Введение}

Ханты-Мансийский автономный округ является одним из главных регионов, где ведутся разведка и добыча углеводородного сырья, которые непосредственно сопровождаются весьма значительным техногенным 
воздействием на окружающую среду. Освоение месторождений углеводородного сырья приводит к изменению биотопов в результате блокирования болотного стока, загрязнению высокоминерализованными водами, вследствие накоплению в экосистемах токсичных и ядовитых элементов. Хлориды хорошо растворяются в воде, образуют с ней систему взаиморастворимых жидкостей. Это стойкие, неразлагающиеся и несорбирующиеся вещества, обладающие высокой миграционной способностью. Поэтому хлориды могут распространяться в водотоках на значительные расстояния и образовывать большие по протяженности и по площади области загрязнения, с последующим их накоплением в донных отложениях.

\section{Цель исследования}

Оценка загрязнения малых рек хлорид-ионами.

\section{Материалы и методы исследования}

В ходе исследования была проведена оценка загрязнения хлорид-ионами поверхностных вод и донных отложений исследуемой реки Нижневартовского района. В ходе исследования были отобраны пробы поверхностных вод и донных отложений исследуемой реки.

\section{Результаты исследования и их обсуждение}

Значения хлоридов в исследованных пробах поверхностных вод исследуемой реки небольшие, по сравнению с ПДК (300 мг/дм³) (рис. 1), и колеблются от 1 мг/дм³ (фоновая точка 1 В) до 2,8 мг/дм³ на территории антропогенного воздействия. Фоновые показатели в течении периода исследования не изменились -1 мг/дм³. Максимальные значения зафиксированы в летне-осенний период исследования в точках $2 \mathrm{~B}, 3 \mathrm{~B}$, 4В - 1,4-2,8 мг/дм³ .

Концентрация хлоридов, в пробах донных отложений, взятых на на исследуемой реке находится в диапазоне 10-382 мг/кг. В фоновой точке (1B) содержание хлоридов в донных отложениях равна 10 мг/кг, а в контрольных точках (2B, 3В, 4B) - 136-385 мг/кг (рис. 2).

Исследования показывают, что концентрация хлоридов в донных отложениях увеличивается вниз по течению реки. Максимальные значения хлоридов 382 мг/кг приходятся на территорию интенсивного воздействия нефтяного хозяйства на окружающую среду (3В), и на территории выхода реки из лицензионного участка происходит некоторое уменьшение значения хлоридов - 275 мг/кг (4В). 


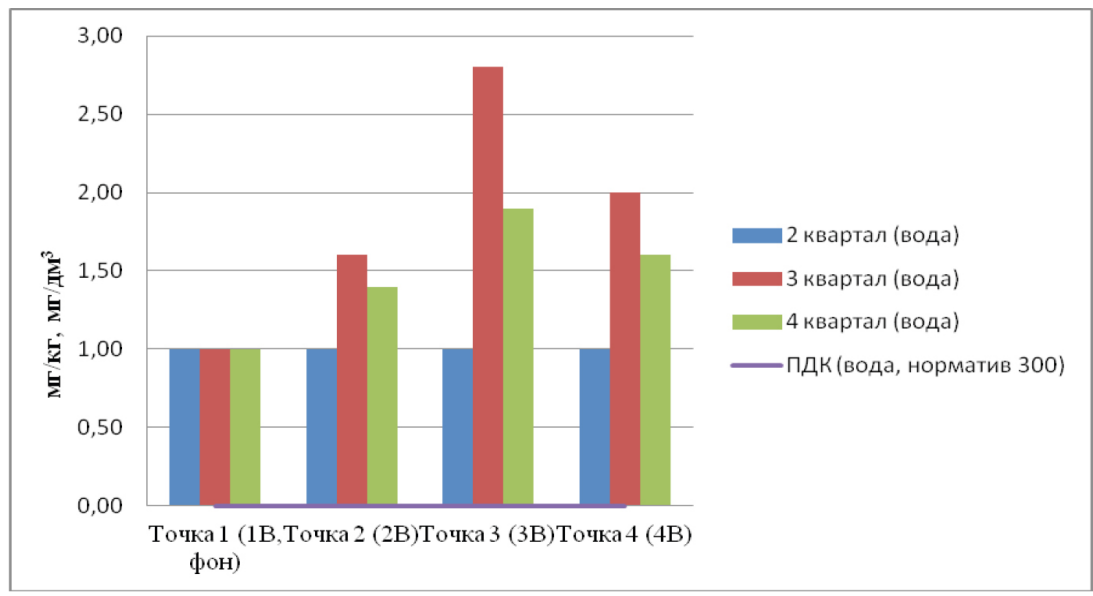

Рис. 1. Содержание хлоридов в поверхностных водах, мг/дм³

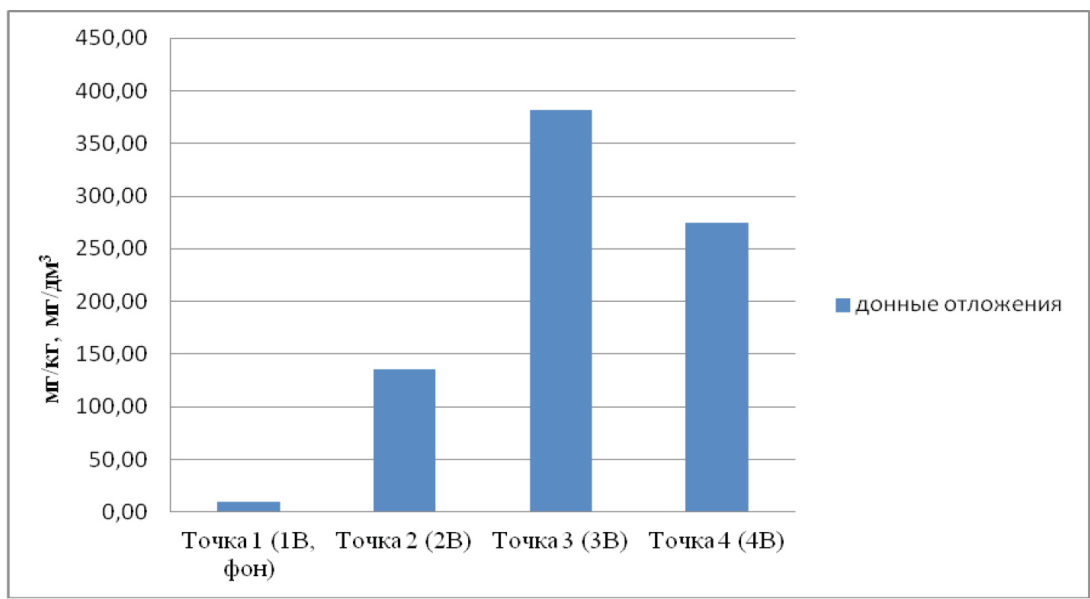

Рис. 2. Содержание хлоридов в донных отложениях, мг/кг

\section{Заключение}

Результаты исследований по содержанию хлоридов в поверхностных водах исследуемой реки показывают, что превышение нормативов не наблюдается. Полученные результаты свидетельствуют, что в донных отложениях происходит накопление хлоридов, особенно на территории нефтегазового месторождения. 


\section{Сиисок литературы}

1. Александрова В.В., Левкова А.Н., Логинов Д.Н., Иванов В.Б. Анализ и прогноз миграции антропогенных примесей в пробах донных отложений поверхностных вод Нижневартовского района // В мире научных открытий. 2017. № 9 (4-2). 180-186.

2. Александрова В.В. Применение метода биотестирования в анализе токсичности природных и сточных вод (на примере Нижневартовского района Тюменской области): Монография. Нижневартовск: Изд-во НГГУ, 2009. $92 \mathrm{c}$.

3. Александрова В.В. Анализ корреляционной зависимости выживаемости и плодовитости тест-объекта Ceriodaphnia affinis с химическим составом воды // Вестник Нижневартовского государственного университета. 2013. № 3. С. 60-63.

4. Александрова В.В. Определение качества природных вод методом биотестирования в полевых условиях // Известия Самарского научного центра Российской академии наук. 2013. Т. 15. № 3 (3). С. 897-899.

5. Александрова В.В., Левкова А.Н., Иванова А.В. Анализ и прогноз миграции химических веществ в поверхностных водах и донных отложениях малых рек // Siberian Journal of Life Sciences and Agriculture. 2019. T. 11. №2-2. C. 12-20.

6. Александрова В.В., Иванов В.Б., Иванов Н.А., Марач В.С. Оценка качества воды озер Нижневартовского района по критерию выживаемости Daphnia magna // В мире научных открытий». 2017. Т. 9. № 1-2. С. 36-41.

7. Александрова В.В. Биотестирование как современный метод оценки токсичности природных и сточных вод. Нижневартовск, 2013.

8. Александрова В.В., Иванов Н.А., Марач В.С., Иванов В.Б. Оценка токсичности вод озер Нижневартовского района // В мире научных открытий. 2017. T. 9. № 2-2. С. 53-57.

9. Александрова В.В., Логинов Д.Н., Войтова В.А. Корреляционный анализ миграции антропогенных примесей в донных отложениях методом химического анализа // В мире научных открытий. 2017. Т. 9. № 4-2. С. 186-191.

10. Волков И.М., Ряхин М.С., Белоусов С.Н., Александрова В.В., Иванов В.Б. Обеспечение экологической безопасности проектных решений на территории лицензионных участков недропользователей с применением наилучших доступных технологий // Нефтяное хозяйство. 2018. № 2. С.109-112.

11. Иванов В.Б., Усманов И.Ю., Александрова В.В., Иванов Н.А., Болотин К.И., Иванова Л.Г., Копылов Е.О. Количественные и качественные критерии преобразования и самовосстановления природных комплексов в ре- 
зультате загрязнения нефтепродуктами // В мире научных открытий. 2017. T. 9 (1-2). C. 56-65.

12. Иванов В.Б., Усманов И.Ю., Александрова В.В., Иванов Н.А., Калиновская Е.А. Оценка воздействия нефтешламовых амбаров на верховые болотные почвы // В мире научных открытий. 2017. Т. 9 (1-2). С. 66-71.

13. Иванов В.Б., Федоренко Л.З., Иванова Л.Г. Оценка сезонной динамики качества поверхностных вод по критерию плодовитости Ceriodaphnia affinis // В мире научных открытий. 2018. Т. 10. № 1-2. С. 38-45.

14. Иванов В.Б., Долгих А.Ю. Оценка экологического состояния водного объекта // Siberian Journal of Life Sciences and Agriculture. 2019. Т. 11. № 3-2. C. 21-28.

15. Левкова А.Н., Иванов В.Б. Эколого-химический анализ состояния донных отложений малых рек Нижневартовского района в зоне воздействия нефтедобывающей промышленности // XIX Всероссийская студенческая научно-практическая конференция Нижневартовского государственного университета. Нижневартовск: Изд-во НВГУ, 2017. С. 355-360.

16. Толкачева В.В. Анализ токсичности природных вод методом биотестирования (на примере Нижневартовского района) : Автореферат диссертации на соискание ученой степени кандидата биологических наук. Омск: ОмГПУ, 2004. $22 \mathrm{c}$.

17. Усманов И.Ю., Иванов В.Б., Иванов Н.А. Самовосстановление экосистем Среднего Приобья при антропогенных воздействиях нефтедобывающего комплекса // Экологические проблемы бассейнов крупных рек - 6: Материалы международной конференции. Тольятти: Анна, 2018. С. 303-305.

18. Шорникова Е.А. Диагностика состояния экосистем водотоков на лицензионных участках нефтяных месторождений Среднего Приобья // Электронный научный журнал «Нефтегазовое дело». 2007. №1. http://ogbus. $\mathrm{ru} /$ article/view/diagnostika-sostoyaniya-ekosistem-vodotokov-na-licenzionnyx-uchastkax-neftyanyx-mestorozhdenij-srednego-priobya

19. Ivanov V.B., Alexandrova V.V., Usmanov I.Yu., Scherbakov A.V., Yumagulova E.R, Ivanov N.A., Chibrikov O.V. Comparative Evaluation of Migrating Anthropogenic Impurities in Ecosystems of the Middle Ob Region through Bioindication and Chemical Analysis // Vegetos: An International Journal of Plant Research. 2016. Vol. 29. № 2, pp. 47-50.

\section{References}

1. Aleksandrova V.V., Levkova A.N., Loginov D.N., Ivanov V.B. V mire nauchnyh otkrytij. 2017. №9 (4-2), pp. 180-186. 
2. Aleksandrova V.V. Primenenie metoda biotestirovaniya $v$ analize toksichnosti prirodnyh i stochnyh vod (na primere Nizhnevartovskogo rajona Tyumenskoj oblasti) [Application of the bioassay method in the analysis of toxicity of natural and waste waters (for example, Nizhnevartovsk district of the Tyumen region)]. Nizhnevartovsk: Izd-vo NGGU, 2009. 92 p.

3. Aleksandrova V.V. Vestnik Nizhnevartovskogo gosudarstvennogo universiteta. 2013. № 3, pp. 60-63.

4. Aleksandrova V.V. Izvestiya Samarskogo nauchnogo centra Rossijskoj akademii nauk. 2013. V. 15. № 3 (3), pp. 897-899.

5. Aleksandrova V.V., Levkova A.N., Ivanova A.V. Siberian Journal of Life Sciences and Agriculture. 2019. V. 11. №2-2, pp. 12-20.

6. Aleksandrova V.V., Ivanov V.B., Ivanov N.A., Marach V.S. V mire nauchnyh otkrytij. 2017. V. 9. № 1-2, pp. 36-41.

7. Aleksandrova V.V. Biotestirovanie kak sovremennyj metod ocenki toksichnosti prirodnyh i stochnyh vod [Biotesting as a modern method for assessing the toxicity of natural and waste waters]. Nizhnevartovsk, 2013.

8. Aleksandrova V.V., Ivanov N.A., Marach V.S., Ivanov V.B. V mire nauchnyh otkrytij. 2017. V. 9. № 2-2, pp. 53-57.

9. Aleksandrova V.V., Loginov D.N., Vojtova V.A. Vmire nauchnyh otkrytij. 2017. V. 9. № 4-2, pp. 186-191.

10. Volkov I.M., Ryahin M.S., Belousov S.N., Aleksandrova V.V., Ivanov V.B. Neftyanoe hozyajstvo. 2018. № 2, pp. 109-112.

11. Ivanov V.B., Usmanov I.Yu., Aleksandrova V.V., Ivanov N.A., Bolotin K.I., Ivanova L.G., Kopylov E.O. V mire nauchnyh otkrytij. 2017. V.9 (1-2), pp. 56-65.

12. Ivanov V.B., Usmanov I.Yu., Aleksandrova V.V., Ivanov N.A., Kalinovskaya E.A. V mire nauchnyh otkrytij. 2017. V. 9 (1-2), pp. 66-71.

13. Ivanov V.B., Fedorenko L.Z., Ivanova L.G. V mire nauchnyh otkrytij. 2018. V. 10. № 1-2, pp. 38-45.

14. Ivanov V.B., Dolgih A.Yu. Siberian Journal of Life Sciences and Agriculture. 2019. V. 11. № 3-2, pp. 21-28.

15. Levkova A.N., Ivanov V.B. XIX Vserossijskaya studencheskaya nauchno-prakticheskaya konferenciya Nizhnevartovskogo gosudarstvennogo universiteta [XIX All-Russian Student Scientific and Practical Conference of the Nizhnevartovsk State University]. Nizhnevartovsk: Izd-vo NVGU, 2017, pp. 355-360.

16. Tolkacheva V.V. Analiz toksichnosti prirodnyh vod metodom biotestirovaniya [The analysis of the toxicity of natural waters by the bioassay method (on the example of the Nizhnevartovsk region)]. Omsk: OmGPU, 2004. 22 p. 
17. Usmanov I.YU., Ivanov V.B., Ivanov N.A. Ekologicheskie problemy bassejnov krupnyh rek-6: Materialy mezhdunarodnoj konferencii [Ecological problems of large river basins - 6: Materials of an international conferenc]. Tol'yatti: Anna, 2018, pp. 303-305.

18. Shornikova E.A. Neftegazovoe delo. 2007. №1. http://ogbus.ru/article/view/ diagnostika-sostoyaniya-ekosistem-vodotokov-na-licenzionnyx-uchastkax-neftyanyx-mestorozhdenij-srednego-priobya

19. Ivanov V.B., Alexandrova V.V., Usmanov I.Yu., Scherbakov A.V., Yumagulova E.R, Ivanov N.A., Chibrikov O.V. Comparative Evaluation of Migrating Anthropogenic Impurities in Ecosystems of the Middle Ob Region through Bioindication and Chemical Analysis. Vegetos: An International Journal of Plant Research. 2016. Vol. 29. № 2, pp. 47-50.

\section{ДАННЫЕ ОБ АВТОРАХ}

Алагулов Денис Андреевич, студент

ФГБОУ ВО «Нижневартовский государственный университет» ул. Ленина, 56, г. Нижневартовск, 628605, Российская Федераџия

Иванова Ангелина Вячеславовна, студент

ФГБОУ ВО «Нижневартовский государственный университет» ул. Ленина, 56, г. Нижневартовск, 628605, Российская Федерация karatazh@mail.ru

DATA ABOUT THE AUTHORS

Alagulov Denis Andreevich, student

Nizhnevartovsk State University

56, Lenin St., Nizhnevartovsk, 628605, Russian Federation

Ivanova Angelina Vyacheslavovna, student

Nizhnevartovsk State University

56, Lenin St., Nizhnevartovsk, 628605, Russian Federation

karatazh@mail.ru 